\title{
Peroxisome Proliferator-Activated Receptors as Superior Targets for Treating Diabetic Disease, Design Strategies - Review Article
}

\author{
(1) Mohammed T. QAOUD ${ }^{*}$, (1) Ihab ALMASRI2 , (1) Tijen ÖNKOL ${ }^{1 \psi}$ \\ ${ }^{1}$ Gazi University, Faculty of Pharmacy, Department of Pharmaceutical Chemistry, Ankara, Türkiye \\ 2Al-Azhar University, Faculty of Pharmacy, Department of Pharmaceutical Chemistry and Pharmacognosy, Gaza Strip, Palestine \\ ${ }^{\psi}$ We commemorate late Prof. Dr. Tijen Önkol with mercy and respect on this occasion. IEO, BK, SAE (The Editorial Board)
}

\begin{abstract}
Thiazolidinedione (TZD), a class of drugs that are mainly used to control type 2 diabetes mellitus (T2DM), acts fundamentally as a ligand of peroxisome proliferator-activated receptors (PPARs). Besides activating pathways responsible for glycemic control by enhancing insulin sensitivity and lipid homeostasis, activating PPARs leads to exciting other pathways related to bone formation, inflammation, and cell proliferation. Unfortunately, this diverse effect of activating several pathways may show in some studies adverse health outcomes as osteological, hepatic, cardiovascular, and carcinogenic effects. Thus, a silver demand is present to find and develop new active and potent antiglycemic drugs for treating T2DM. To achieve this goal, the structure of TZD for research is considered a leading structure domain. This review will guide future research in the design of novel TZD derivatives by highlighting the general modifications conducted on the structure component of TZD scaffold affecting their potency, binding efficacy, and selectivity for the control of T2DM.
\end{abstract}

Key words: Peroxisome proliferator-activated receptors, thiazolidinediones, structure-activity relationship, drug design, antidiabetic activity

\section{INTRODUCTION}

This group of metabolic diseases presents because of a defect in insulin action, insulin secretion, or both that finally leads to chronic hyperglycemia is called diabetes mellitus (DM). This proves the importance of insulin as an anabolic hormone in controlling lipid, carbohydrate, and protein metabolic abnormalities. These metabolic abnormalities are due to the low level of insulin secretion that leads to inadequate response or/ and resistance of target tissues to insulin. The insulin resistance occurs at the level of insulin receptors, signal transduction system, and/or effector enzymes or genes of skeletal muscles, mainly targeted tissue, adipose tissue, and to a lesser extent, liver., ${ }^{1,2}$ The duration and type of diabetes are directly related to the severity of symptoms. ${ }^{3}$ To distinguish between DM symptoms and various hypoglycemic cases recorded, it has been assorted into different types. In 1997, DM was classified by the American Diabetes Association (ADA) into four types: type 1, type 2, other types, and gestational DM. ' Until now, this classification adopted by ADA still the most accepted one.
Type 1 DM (T1DM), which is due to the destruction of pancreatic $\beta$-cells. It is also known as the autoimmune T1DM due to the presence of autoantibodies, considered as a hallmark of type 1 , that work against pancreatic $\beta$-cells, although, its role in the disease pathogenesis is unclear. Those autoantibodies are formed against glutamic acid decarboxylases, insulin, islet cell, transporter protein (ZnT8A), and protein tyrosine phosphatase. Before the onset of the disease by months or years, these pancreatic autoantibodies could be present and thus detected in the serum of type 1 patients with DM. Destruction of pancreatic $\beta$-cells is mainly through the humoral ( $\mathrm{B}$-cell) response and insulitis ( $T$-cell mediated inflammatory response). This type shows general symptoms that often develop suddenly, such as lack of energy, polyuria, polydipsia, extreme tiredness, blurred vision, enuresis, slow-healing wounds, and sudden weight loss. Regarding adolescents and children, diabetic ketoacidosis and severe dehydration are developed. T1DM accounts $5-10 \%$ of diabetes cases, in general, and $80-90 \%$ of diabetes in adolescents and children. It is important to notice 
that 78,900 new diabetic cases are recorded per year by the International Diabetes Federation (IDF). ${ }^{4}$ Regarding the adults and adolescences above 14 years of age, type 1 shows a high prevalence, for example, in 2010, total account of type 1 in the United States (USA) was estimated to be 3 million $^{5}$ and, in 2019 was accounted to be 1.93 per $1000 .^{6}$

However, type 2 DM (T2DM), characterized by a high blood glucose level due to insulin resistance besides a relatively low level of insulin, shows a higher global prevalence based on a 2019 report published by the IDF compared to type 1. The report mentioned that the global prevalence of T2DM in adults (2079 years old) was $8.3 \%$ (382 million people), mainly intensify within ages of 40-59. Men show a higher prevalence than women, with 14 million more (184 million women versus 198 million men). Additionally, during pregnancy, 21 million women are diagnosed with the diabetic disease. These accounts by 2035, are predicted to exceed $10.1 \%$ global prevalence with 592 million cases. ${ }^{6-9}$ The IDF Diabetes Atlas (2019), showed the current and expected prevalence of diabetes in adults (20-79 years) for different regions worldwide (Figure 1). As shown, the highest accounts in 2019 were reported to the western Pacific region with 163 million and that is expected to increase to 212 million by 2045 . Additionally, high concerns are directed to the Middle East besides of Africa and North Africa Regions that are expected to report an increase in the total diabetic cases by more than $100 \%$. $80 \%$ of the total cases were counted for the low- and middle-income countries, "where the epidemic is gathering pace at alarming rates". ${ }^{10}$

For patients with DM, for insulin deficiency or resistance, many manifestations have been recognized besides of hyperglycemia, these include essential hypertension, nephropathy, obesity, dyslipidemia, non-alcoholic fatty liver disease, accumulation of lipoprotein, premature adrenarche, ovarian hyper and organism, systemic inflammation, polydipsia, polyphagia besides the aforementioned symptoms for type 1 like weight loss and blurred vision. If the diabetic patient is not controlled, stupor and coma are recognized, and finally, lead to death due to ketoacidosis. Severe dehydration of ketoacidosis, recognized in some pediatric type 2 patients with diabetes, who are not recognized as obese generally lead to misclassification to T1DM. $^{11-13}$

Because $90 \%$ of patients with DM around the world counts to T2DM; so considered as the predominant form, a group of drugs, such as glitazones [thiazolidinediones (TZD)], sulfonylureas, glinides, dipeptidyl peptidase IV inhibitors, gliflozins and biguanides, are developed and used to control T2DM. Unfortunately, all the used drugs present uncontrolled side effects like obesity and hypoglycemia. ${ }^{14}$ One of the most important classes of drugs used to treat T2DM is the TZD class, which acts as an antiglycemic agent by binding avidly to the gamma type of a nuclear receptor called peroxisome proliferator-activated receptor gamma (PPAR- $\gamma$ ).

TZD class of drugs is an orally administered hypoglycemic agent used to treat T2DM alone or along with other orally or injectable hypoglycemic agents. This class includes a group of drugs that, in the late 1990s that is the time of their introduction, were dispensed as a first and a second line for treating T2DM like pioglitazone and rosiglitazone (Figure 2).15 Of glycemic control, TZDs displayed better outcomes and physiological effects than the other approved second line agents like sulfonylurea and, in some cases, other $1^{\text {st }}$ line hypoglycemic agents like metformin. As a result, presenting another

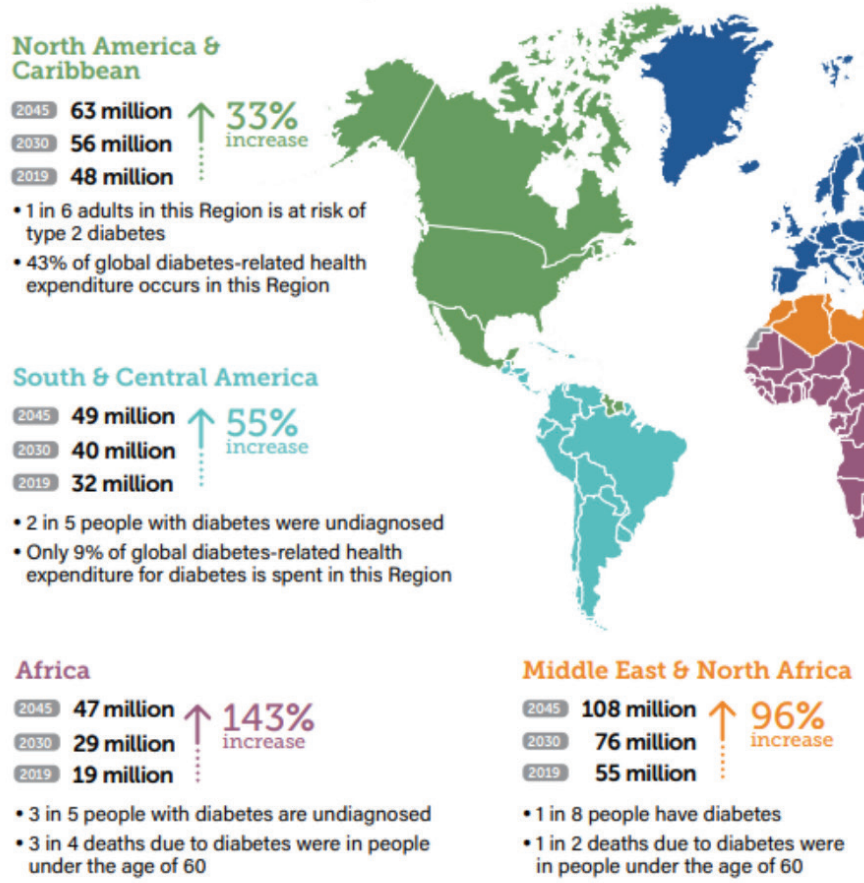

WORLD

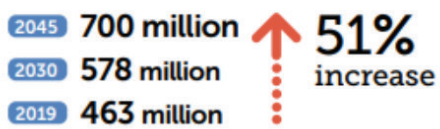

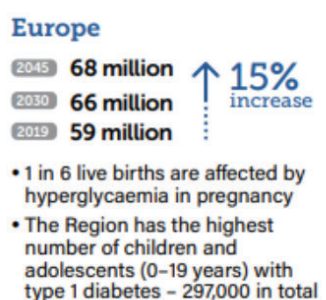

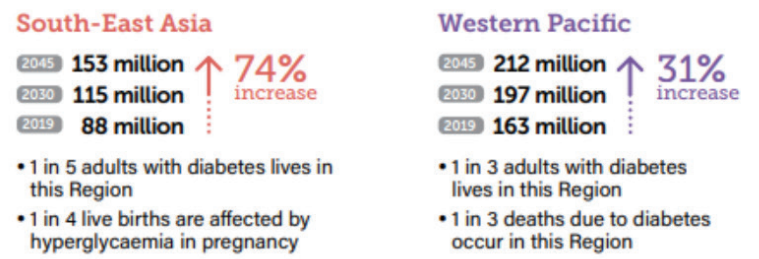

Figure 1. Prevalence of diabetes in adults (20-79 years) in various regions ${ }^{10}$ 
beneficial effect of TZDs, besides controlling hyperglycemia by enhancing insulin sensitivity, like anti-inflammatory effects, its use as antiglycemic agents was praised. ${ }^{16}$

As PPAR receptors exist in different subtypes that differ in structure, effect, and region of distribution, TZD class of drugs mainly activates the gamma subtypes that are exclusively present in adipose and epithelial tissues including urothelium. ${ }^{17}$ However, the gamma subtype also presents in pancreatic $\beta$-cells, liver, immune cells, and bone tissues besides of other subtypes ( $\alpha$ and $\beta$ subtypes). Because of activation of PPAR- $\gamma$ receptors, numerous genes responsible for controlling glucose and lipid metabolism as well as genes that regulate thrombotic function, vascular function, and the inflammatory response are expressed in a different pattern, as up-regulating or down-regulating pattern, and finally leads to both vascular and metabolic effects. Besides, to promote the metabolism of free fatty acids (FFA), TZDs increase the synthesis of triglyceride and non-oxidative glucose disposal, enhance lipid metabolism [raise the level of buoyant and large low-density lipoprotein (LDL) particles and high-density lipoprotein (HDL) level] and lowering the blood pressure besides of improving other common abnormalities related to T2DM like rheological abnormalities and vascular reactivity. ${ }^{18,19}$

Unfortunately, TZDs are accompanied by a set of side effects such as (a) edema and weight gain, which is considered the most common one mainly demonstrated in patients with

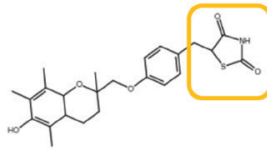

Troglitazone

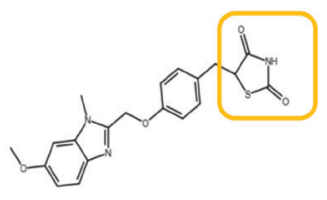

Roveglitazone

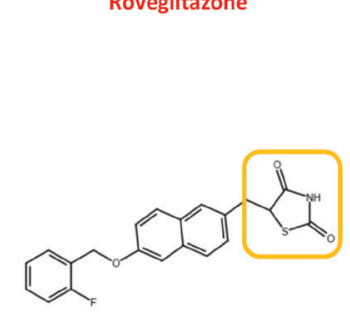

Netoglitazone

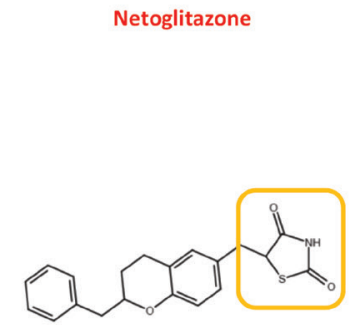

Englitazone
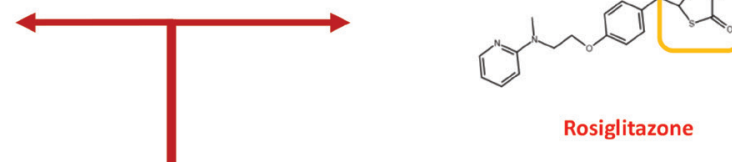

Englitazone

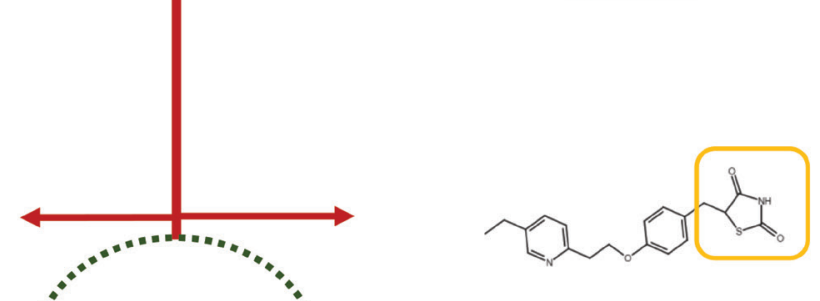

Pioglitazone

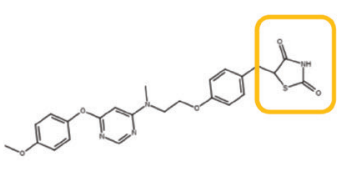

Lobeglitazone

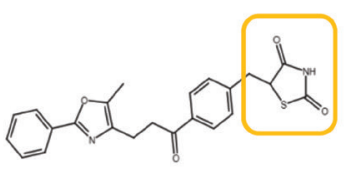

Darglitazone

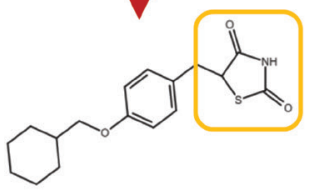

Ciglitazone

Figure 2. Current approved anti-diabetic drugs that follow thiazolidinediones class ${ }^{15}$ 
diabetes, who follow TZDs monotherapy or dual therapy along with other oral hypoglycemic agents or with insulin. ${ }^{18}$ (b) Hepatotoxic effects, including liver failure, were reported for the troglitazone drug (in January 1997, the Food and Drug Administration in USA approved it as the first marketed drug of TZDs class) and sometimes led to demonstrate deaths. (c) Cardiovascular adverse effects like congestive heart failure (CHF) were also reported in the Framingham Heart Study in patients with diabetes administered TZDs. Also, it is well proved that cardiovascular disease is a prevalent complication of T2DM, and administering TZDs led to elevate the risk of CHF in women patients with diabetes to 5 fold and in men patients with diabetes to 2.5 fold, this presents more highlights in the black side of TZDs. ${ }^{15}$ (d) Osteological adverse effects: some records reported that patients with diabetes with T2DM were recognized with an increase in bone mineral density and bone weight. Finally, TZDs were recorded with (e) carcinogenic effects. It has demonstrated that the risk of cancer is accreting to T2DM patients. Many types of cancer have been associated with T2DM, such as liver, gastric, endometrial, pancreatic, renal, ovarian, breast, colon, and bladder cancers. Here, several studies proved the increased rate of cancer mortality rate. $^{20}$

Given above, to diminish the financial burden of T2DM patients and enhance the living equality, many attempts have been conducted by the medicinal chemists to find new antidiabetic agents with better activity and fewer side effects by modifying the existing drugs or discovering new natural leads. To achieve this goal, based on the approved beneficial outcomes of PPAR agonists agents like TZDs on management glucose and lipid metabolism, there is an indispensable need to understand the binding interaction between PPARs and their agonist agents as well as the chemical structure of PPAR. Additionally, to design new ligands with better specificity and binding affinity for PPAR- $\gamma$ or dual as PPAR- $\alpha / \gamma$ agonists, more advanced techniques could be used such quantitative structure-activity relationship (QSAR) and pharmacophore modeling and docking to get a more in-depth knowledge about the TZDs besides of other agonist agents, especially regarding stereochemistry, binding groups, and topology is necessary.

Owing to the meaning of these pharmacological and chemical standpoints, this review will summarize the PPAR- $\alpha, \beta$, and $\gamma$ functions and chemical structures. As well, the existing chemical structures of TZDs will be discussed with respect to their agonist effects on PPAR- $\gamma$ or PPAR- $\alpha / \gamma$ besides outlining the adverse outcomes specified in the literature. Additionally, we going to delineate the pivotal TZD structures to lead the future attempts to develop the next generation PPAR- $\gamma$ or PPAR- $\alpha / \gamma$ agonists as new glitter antidiabetic agents.

Most plant and animal cells that undergo various metabolic functions like cholesterol metabolism, $\mathrm{H}_{2} \mathrm{O}_{2}$-based respiration, and $\beta$-oxidation of FAs generally contain subcellular organelles called PPARs proteins, firstly recognized in 1990, belong to the nuclear hormone receptor superfamily that includes 48 members. ${ }^{21}$ From the structure perspective, there is a similarity between the thyroid or steroid hormone receptors and PPARs. As well, the similarity is extended by their responses to small lipophilic ligands. As PPARs exist is three subtypes, each one responsible for mediating the physiological action of huge diverse FAs and fatty acids-derived molecules.

\section{PPAR isoforms}

PPARs belong to the nuclear receptor superfamily, which is considered a wide diverse superfamily that constitutes much members such as transcription factors, such as PPARs, glucocorticoid receptors, vitamin D, estrogen, retinoic acid, thyroid in addition to several other protein factors associated with xenobiotic metabolism. As heterodimers, PPARs with retinoid $X$ receptor $(R X R)$ act on DNA response elements. The lipid-derived elements are considered to be the innate activating ligands of PPARs. Three subtypes of PPARs $(\alpha, \beta$, and $\gamma)$ present a fundamental role in energy metabolism; however, the activity spectrum and specificity of these subtypes are different. Regarding PPAR- $\gamma$, exists mainly in vascular smooth muscle and endothelial cells and works predominantly in regulating energy storage. PPAR- $\alpha$ presents mainly in the liver but, in the bone, heart, and muscle tissues expressed to a lesser extent. The last subtype (PPAR- $\beta$ ) plays a major role in regulating energy expenditure and displays a ubiquitous expression in the whole body. ${ }^{22}$

\section{Mechanism of action of PPARs}

Various genes are transrexpressed and transactivated as a because of binding peroxisome proliferator response elements (PPREs), which exist at the promoter of a target gene that consists of direct repeats of AGGTCA, with a heterodimer complex composed of PPARs and RXR. In the case of no ligands are present, the gene transcription is blocked because of the corepressor complex role associated with thesis heterodimers. Balakumar et al., 232007 mentioned that some agonist ligands act on PPARs. RXR, like PPAR, presents as three subtypes: RXR- $\alpha$, $\beta$, and $\gamma$. 9-cis-retinoic acid acts as an endogenous agonist to all distracted isoforms. ${ }^{24}$ With respect to these isoforms within the RXR-PPAR complex, no appointed actions have yet been confirmed. Whilst, antidiabetic action could be obtained through activating the heterodimers complex with retinoids (synthetic RXR agonist), this action is comparable to PPAR agonist effect recognized in mouse models of T2DM. The heterodimerization of RXR with PPARs is facilitated by the ligand-binding domain (LBD) and eventual RXR-PPAR complex, with recruitment of co-factors, subsequently binds to PPRE as briefly shown in Figure 3. ${ }^{25}$

Binding of DNA with RXR/PPAR complex is blocked in the absence of agonists/ligands by a group of co-repressor structures such as G-protein pathway suppressor 2, histone deacetylases, and nuclear receptor co-repressors, high-affinity complexes are formed between the inert heterodimers of RXRPPAR and these co-repressors. To initiate the transcription process, various transcriptional co-activators/co-factors such as steroid receptor coactivator-1, CREB binding protein, histone acetyltransferase $\mathrm{p} 300$, and PPAR coactivator -1 are recruited. ${ }^{26}$ 


\section{PPAR structure}

Figure 4 represents the structure of PPARs as one dimension shape. Many advanced techniques have been incorporated to study the PPAR structure extensively like solvent mapping techniques, molecular modeling, and X-ray crystallography with respect to main structural domains including LBD, coactivator binding site (Co-FBD), and DNA binding domain/region (DBD). This finally led provides insight into the binding mode. PPAR- $\gamma$ is comprehensively studded in-depth, other than other subtypes, including interactions and structure. Additionally, it is examined in different cases such as the presence or absence of the ligands, co-activator peptides in a DNA bound or unbound state, and as heterodimers with RXR- $\alpha$ or as homodimers. It was proved that $N$-terminal ( $\left.5^{\prime}\right)$, involved in the phosphorylation of PPAR, contains DBD but the C-terminal ( $3^{\prime}$ ) contains the LBD as demonstrated in the 3-D structure of PPARs. ${ }^{27} 5^{\prime}-A F-$ 1 domain associated with a region that is independent of $A / B$ domain that is responsible for the phosphorylation of PPAR.

In the promoter region of target gene, peroxisome proliferation response element (PPRE) binds to DNA. The co-FBD/D domain especially binds to co-factors. The binding of specific small molecules to LBD or E/F domain leads to sequential gene expression because of receptor activation. The E/F domain contains a ligand-dependent region called the AF-2 region, which facilitates gene transcription process. ${ }^{28}$

\section{Structure of DNA binding domain of PPARs}

A/B domain of PPARs plays a substantial role in protein phosphorylation, works as a functional activator of the transcriptional process, or interacts directly with other regulatory proteins or receptor domains. Additionally, this region does not possess a significant binding side due to the absence of conserved amino acid sequence or residues of high hydrophobic character due to its high mobility. PPAR $-\gamma$ ligands were recorded with no action on the region of $A / B$. In the highly conserved and central DNA binding domain, two binding sites of zinc are recognized. As also, architectural elements are present with the ability for sequence-specific binding to DNA. ${ }^{29,30}$ Beyond short carboxy terminal extensions (CTE), DBD structure of nuclear receptors was not visualized. Examining the RTX/PPAR- $\gamma$ complex in depth has demonstrated that the polarity in PPAR- $\gamma$ is mainly based on CTE. The structure of DBD showed a close vicinity to LBD structure after investigation the structures of PPAR- $\gamma$ in-depth.

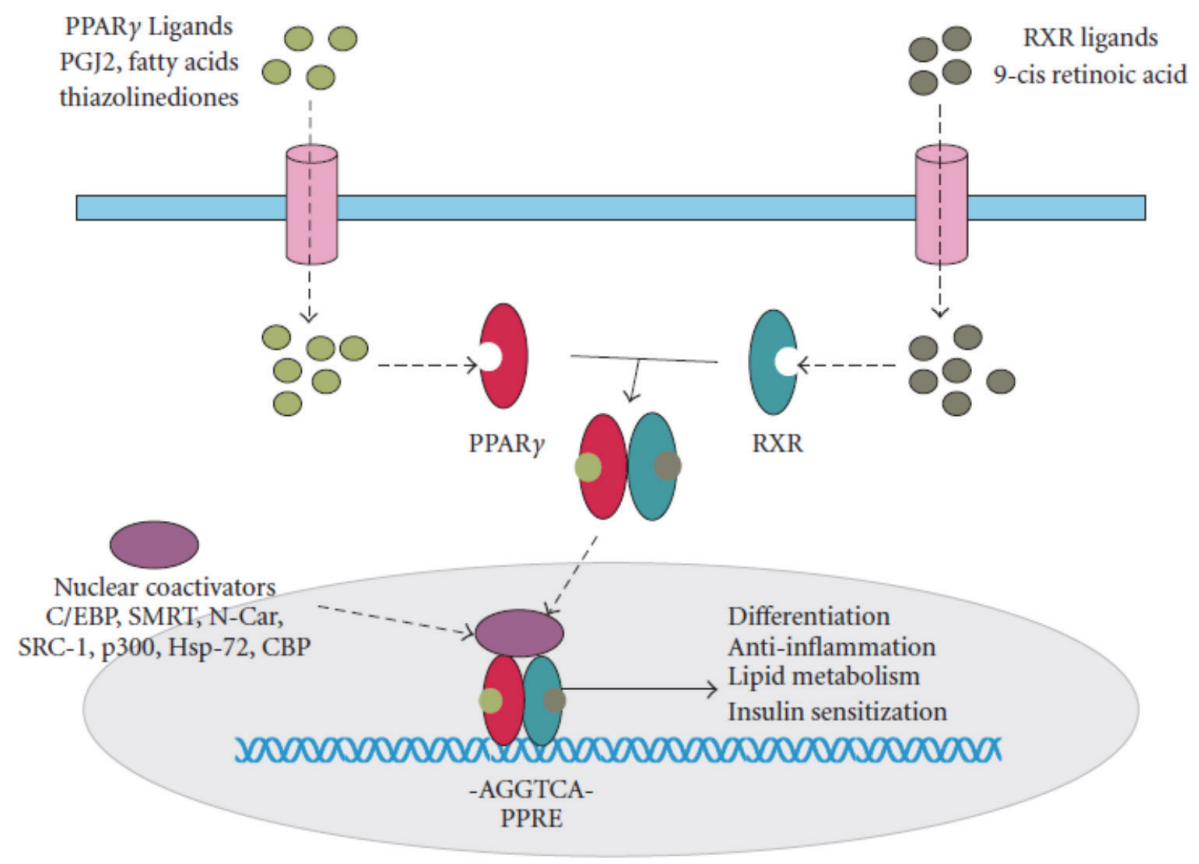

Figure 3. Current mode of action for PPAR- $\gamma$. PPAR- $\gamma$ and RXR form a heterodimer, which is activated by the respective ligands. The activated PPAR- $\gamma /$ RXR heterodimer will be translocated into nucleus and regulates downstream target genes in concert with nuclear receptor coactivator ${ }^{25}$

PPAR: Peroxisome proliferator-activated receptor, RXR: Retinoid X receptor

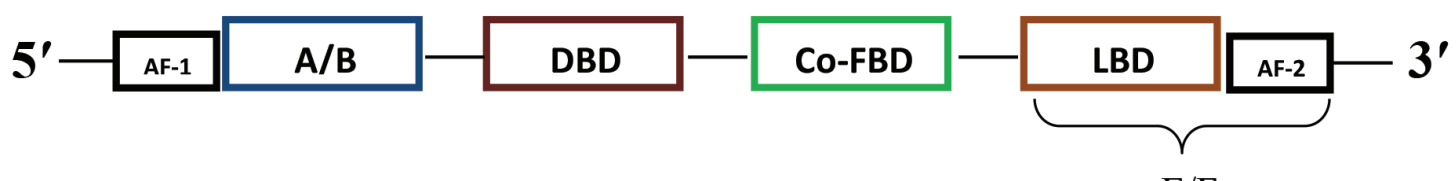

$\mathrm{E} / \mathrm{F}$

Figure 4. One-dimensional structure of the different binding domains of PPARs ${ }^{28}$

DBD: DNA binding domain/region, Co-FBD: Co-activator binding, LBD: Ligand-binding domain, PPARs: Peroxisome proliferator-activated receptors 


\section{Structure of ligand binding domain of PPARs}

Various endogenous ligands like FAs including their metabolites considered agonist ligands PPARs isoforms $(\alpha, \beta$, and $\gamma){ }^{31}$ Examining the LBD structure of these three isoforms using the $X$-ray crystallographic technique showed similar structures. As shown in Figure 5A, the LBD of PPARs structurally consists of thirteen $\alpha$-helices, $\mathrm{H} 1-\mathrm{H} 12$, and $\mathrm{H} 2$ ' helices, besides small fourstranded $\beta$-sheets, S1-S4, folded into a single region/domain. LBD with respect to the secondary structure shows a sandwichlike structure of three layers of antiparallel $\alpha$-helices. The three long helices $(\mathrm{H} 3, \mathrm{H} 7$, and $\mathrm{H} 10 / \mathrm{H} 11)$ make up the two outer layers of the sandwich. The helices that made up the middle layer $(\mathrm{H} 4$, $\mathrm{H} 5, \mathrm{H} 8$, and H9) are absent from the bottom half of the domain while building the top half. Thus, for ligand binding function, this middle layer exists a large binding cavity $\left(\sim 1400 A^{\circ}\right)$ that displays a $Y$ shape with three arms. This distinct structure of the binding site plays a major role in facilitating the interaction/ binding with diverse structure ligands like presenting various conformations with different functional groups or ligands with single/branched chains. ${ }^{32-34}$

In and out $Y$ shape cavity, ten meaningful binding sites ( $P 1-P 4$, $E 1, E 2, C 1, C 2, B$, and F) have been reported and characterized using solvent mapping techniques on the RXR/PPAR- $\gamma$ heterodimers, as shown in Figure 5B. Only the four binding sites (P1-P4) exist inside the Y-shape binding cavity of the LBD, while, the other six binding sites are present outside the region. The binding sites E1 and E2 present in the entrance region unlike $B$ and $F$ binding sites, which present in the surface of the $\mathrm{Y}$-shape binding region. Regarding the $\mathrm{C} 1$ and $\mathrm{C} 2$ binding sites, they are present in the co-activator binding region.

With respect to $\mathrm{P} 1$ and $\mathrm{P} 2$ binding sites, they constitute a significant hydrophobic pocket that functions as an excellent binding target for all agonists that interact with H12. Examples that could interact with the residues in this binding region are the polar nucleus and carboxyl head group of TZDs and ragaglitazar (a partial agonist ligand), respectively. Compared to P1 and P2 binding sites that are located at arm-I, the P3 and P4 binding sites were present at arm-II and make up a larger hydrophobic pocket. The E2 binding site, the main ligand entrance site, also exhibits a hydrophobic behavior that located at arm-III. The actions including interaction with co-activators and dimerization with RXR are related to the other binding sites located outside the $\mathrm{Y}$-shape cavity. ${ }^{34}$

\section{Structural variations between LBD of PPAR- $\alpha$ and $\gamma$}

PPAR- $\alpha$ isoform, as well as PPAR- $\gamma$ isoform, constitute 34 amino acid residues with respect to the $Y$-shaped binding region of LBD. A high percentage of similarity, around $80 \%$, regarding the size of the binding cavity and the amino acid constituent has been recognized in both isoforms. The ligand specificity of PPARs is a result of the minor differences in the topology, arm-I presents two minor differences in amino acid residues. As the binding sites present in this arm interact mainly with the polar head groups of ligands, these differences in amino acid residues (even these changes are minor) lead to a significant influence on the ligand specificity. The amino acid residues, His323 and Phe363 located at the arm-I of PPAR- $\gamma_{\text {. }}$ are replaced by Tyr314 and Ile354 for PPAR- $\alpha$, respectively. With respect to arm-II, the Gly284 amino acid residue of PPAR- $\gamma$ is replaced by a bulky lipophilic Cys 275 residue in PPAR- $\alpha$. The ligand entrance site, located at arm-III, presents a remarkable difference represented by the replacement of Arg288 residue of PPAR $-\gamma$ by $\operatorname{Tr} 279$ in PPAR- $\alpha .{ }^{27}$

\section{SAR studies on TZDs}

Medicinal chemistry has an integral mission in relating the molecular structure to its pharmacological effect. To improve
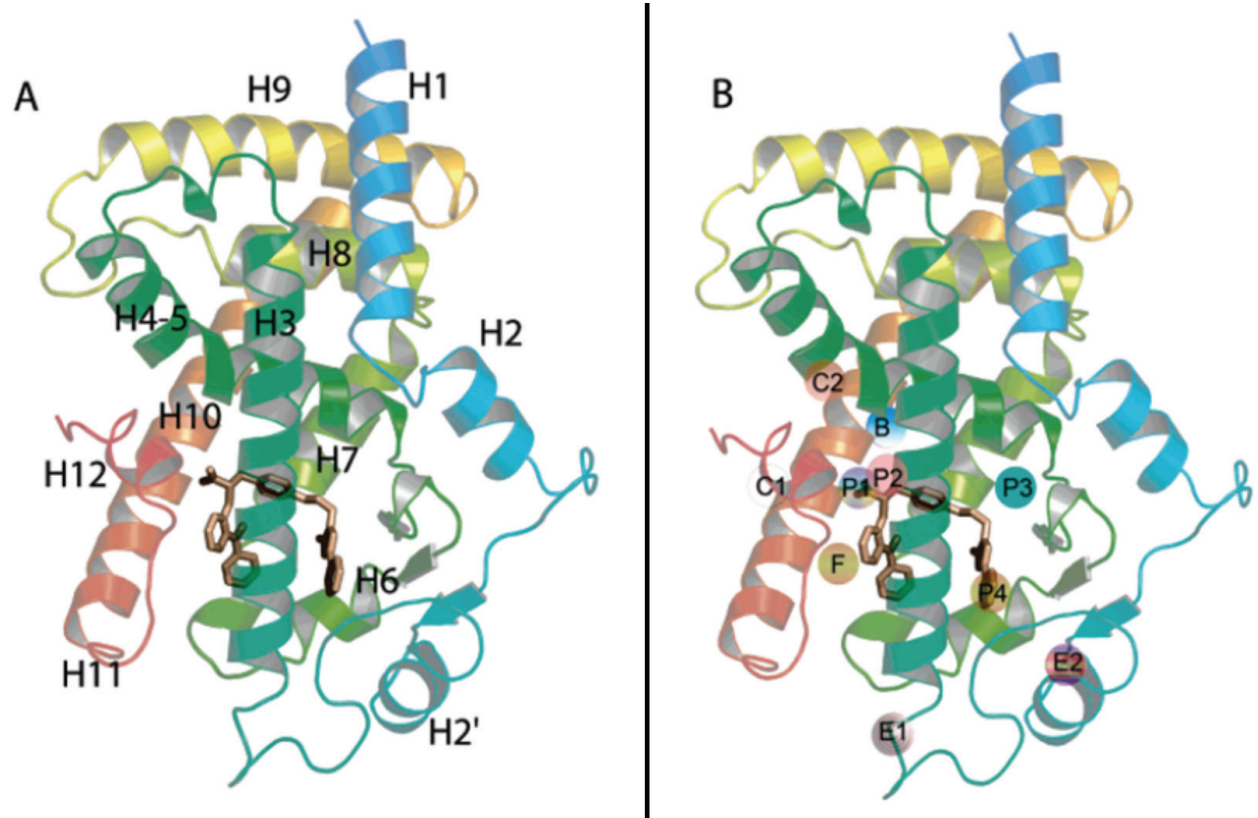

Figure 5. Structure of the PPAR- $\gamma$ LBD. (A) Polypeptide backbone is shown as a cartoon, indicating the $12 \mathrm{R}$ helices that comprise the domain ${ }^{34}$ PPARs: Peroxisome proliferator-activated receptors, LBD: Ligand-binding domain 
the molecular pharmacodynamic and pharmacokinetic properties of a leading drug, including decreasing adverse effects, improving potency and selectivity and enhancing bioavailability, assessing the mode and nature of binding as well as figuring out the pharmacophores is indispensable. For pharmacophore identification, trying to screen, recognize, and synthesize prototype analogs is a common method to get reliable results. However, this approach is time-consuming and is considered an old approach. Currently, various sophisticated advanced computer programs are employed extensively in the drug modification, design, and discovery application.

As a result, to develop new synthetic PPAR- $\gamma$ agonists, TZDs have been suggested to be stereotype molecules for developing. With respect to the literature, as shown in Figure 6, a simplified topology of a typical synthetic TZD is identified. As shown, the topology structure exhibits a "U" shaped geometry. The head is a TZD functional group, which exhibits polar and acidic character. Linker-1 (L1) should not exceed three carbon atoms in length whilst, linker-2 (L2) could be extended up to four carbon/hetero atoms. The Ar symbol represents a central heteroaromatic/aromatic ring. The tail position should be represented by a bulky lipophilic group like heteroaromatic/ aromatic rings. ${ }^{35}$

\section{Significance of TZD structure and its binding interactions}

$\mathrm{L} 1$ is directly connected to the position 5 of a ring nucleus, thiazolidine-2,4-dione ring, in TZDs (glitazones). With respect to a series of glitazones hypoglycemic agents, i.e. rosiglitazone (1) and pioglitazone (2) (Figure 7) are taken as the lead molecules. ${ }^{36}$ To control T2DM, an interesting area of research in structural modifications has been directed to these two antidiabetic agents to develop and design new drugs with better profiles. PPAR- $\gamma$, in general, considered as a specific, agonist, and strong target for TZD derivatives via two styles: The Van der Waals and hydrophobic interactions are employed to bind with lipophilic ligands and, $\mathrm{H}$-bonds are employed to bind with polar acidic ligands. ${ }^{36}$ Thus, TZDs have a lipophilic acid behavior, of which the lipophilic binding sites in arm-II and arm-III interact with the lipophilic tail residues of TZDs, while the hydrophilic binding site (P1) existing in arm-I interacts with the acidic head group of TZDs. The aliphatic linkers play a significant role in achieving an efficient binding by acting as spacers; thus the functional groups of TZDs (lipophilic tail and head group) could be positioned properly with the corresponding binding sites of the receptor. Further hydrophobic interaction is obtained from the central phenyl ring. The binding interactions of LBD of PPAR- $\gamma$ with rosiglitazone antidiabetic drug are sorted out in Figure 8. As shown, rosiglitazone forms a U-shaped conformation through interaction with helix-12.37,38

The residues associated with forming $\mathrm{H}$-bond with the acidic head group of TZDs are the Tyr473 of helix-12, His449 of helix-11, and His323 of helix-4. Additionally, through acting as both $\mathrm{H}$-bond donors and acceptors, the oxygen and nitrogen atoms of the nucleus ring could form $\mathrm{H}$-bond with Ser289 (located at helix-3). The $\beta$ strand besides $\alpha$-helix 3, 5, 6, and 7, located at arm-II and arm-III of LBD, mainly participate in interacting with the hydrophobic tail moiety of rosiglitazone, which accounts for the potency and efficiency of the binding profile. Helix-3 shows additional hydrophobic interaction with the central phenyl ring. ${ }^{39}$

The ligand binding and co-activators, not the only factors that control the transcriptional activity of PPAR- $\gamma$, the state phosphorylation plays a major role as well. For example, many studies have reported that the phosphorylation of Ser273 residue of PPAR- $\gamma$ led to obesity development. In the case of the rosiglitazone diabetic drug, this phosphorylation is suppressed. ${ }^{40}$

Several research attempts have been conducted to find new TZD derivatives with better therapeutic profiles by improving insulin sensitivity, anti-inflammatory, and anti-cancer effects, as well as decreasing their adverse effects. ${ }^{41,42}$ The thiazolidine2,4-dione ring (nucleus ring of TZDs) has never been subjected to modification, indicating the significance of this moiety. However, a range of heteroaryl, aryl or lipophilic chain

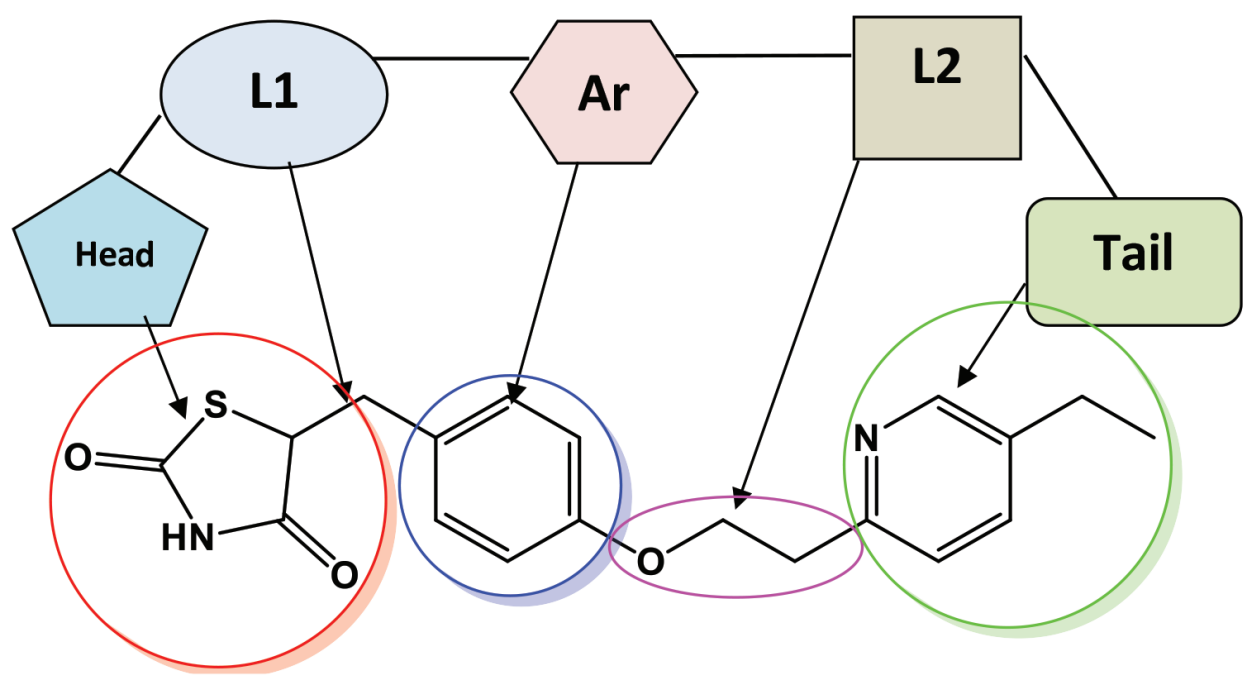

Figure 6. Simplified topology of a typical synthetic thiazolidinedione (pioglitazone) $)^{35}$ 
substituents could be linked to the nucleus ring to develop new antidiabetic agents with better pharmacodynamic and pharmacokinetic profiles. ${ }^{43}$

\section{Modifications on L1}

The linker methylene carbon atom located between the central phenyl ring and the nucleus ring of TZDs is displayed in rosiglitazone and pioglitazone (Figure 7 ). Besides beneficial effects of rosiglitazone by enhancing insulin sensitivity, it displayed a protective effect on the myocardium. The previous studies demonstrated that to retain antidiabetic activity of glitazones, a maximum three carbon atom length of the straight alkyl chain is essential. Branching in the structure is shown if the L1 exceeds the length of the three carbon atoms. The unsaturated bulky alkyl linker in compound (3), Figure 7, provides additional hydrophobic interaction, which leads to improved molecular binding efficiency. ${ }^{44}$ Thus, the length and nature of the alkyl linker should be retained, so the space created presents an excellent fitting between functional groups of ligands and the binding cavities of the LBD. The polar residues located at the binding site corresponding to $L 1$ do not exhibit any electrostatic interaction. Hence, the linkers are

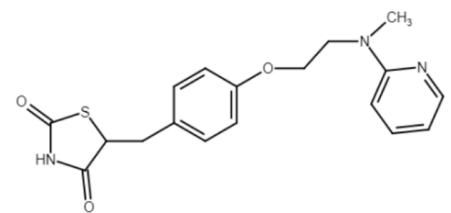

Compound 1

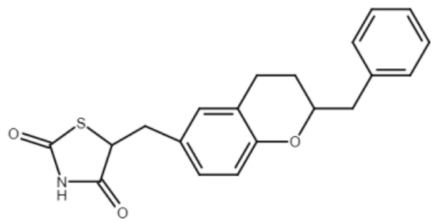

Compound 4<smiles>CC(CCc1ccc(O)c2ccccc12)=C1SC(=O)NC1=O</smiles>

Compound 2<smiles>O=C1NC(=O)C(Cc2ccc3cc(OCc4ccccc4F)ccc3c2)S1</smiles>

Compound 5

A

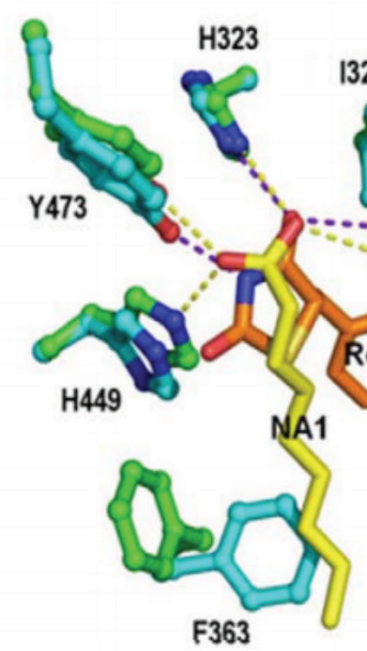

326

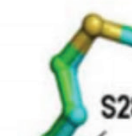

M329

S289

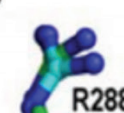

L333

NA2

1341

B

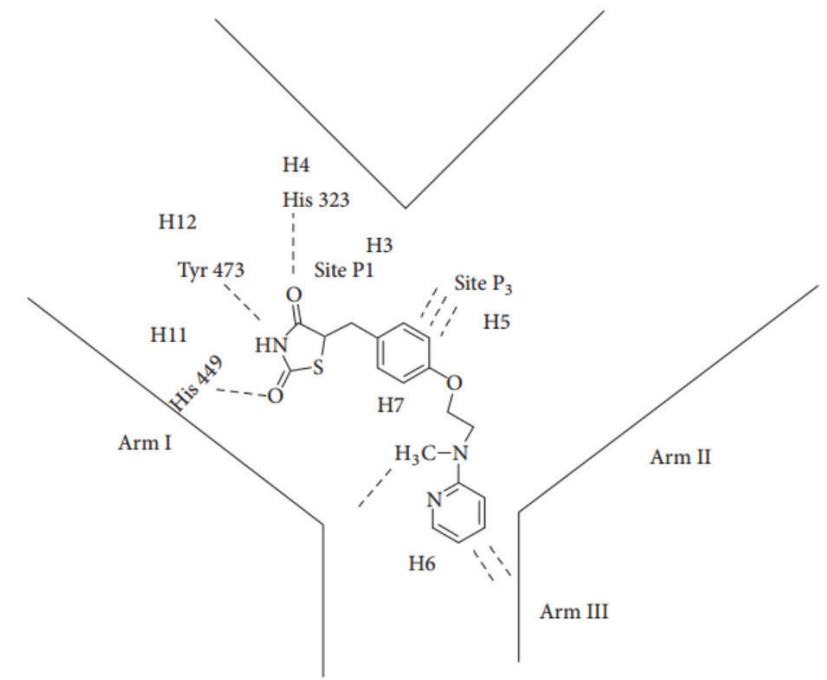

Figure 8. (A) Rosiglitazone binding mode with PPAR $-\gamma$ (PPAR- $\gamma$ blue, ligand transparent pink) in the presence of NA (nonanoic acid) (PPAR- $\gamma$ green, ligand yellow). (B) Binding interactions of rosiglitazone with PPAR- $\gamma$ revealing the three binding arms within the ligand binding domain ${ }^{35,38}$

PPAR: Peroxisome proliferator-activated receptor 
usually represented as aliphatic/hydrocarbon chains without an electronegative atom.

\section{Modifications on central phenyl ring}

The aromatic group center plays a major role in the overall ligand activity by introducing hydrophobic interactions with LBD of PPAR- $\gamma$, especially with helix 3 . With respect to all classical series of glitazones, except englitazone (4) and netoglitazone (5), shown in Figure 7, the aromatic group center is represented by a phenyl ring. With respect to the englitazone ligand (acts as a strong agonist for PPAR- $\gamma$ ), the central aromatic ring is represented by benzdihydropyran whilst, naphthyl moiety is used to occupies the central position for netoglitazone (agonist ligand for PPAR- $\alpha$ and $\gamma$ ). This dual-action of netoglitazone may play a role in minimizing the ligand effect on body weight, to controlling obesity, because of creating partial adipogenesis. ${ }^{45,46}$ Thus, it is considered a potential candidate for T2DM patients, who are accompanied by high cardiovascular risk and obesity. ${ }^{47}$ This indicates that the binding mode of glitazones is mainly influenced by modifying the central ring structure, so the ability to modify agonist properties, including potency and selectivity as well as minimize adverse effects.

\section{Modifications on L2}

$\mathrm{L} 2$ exists between the hydrophobic tail and the central aromatic ring. With respect to rosiglitazone (1) as displayed in Figure 7, $\mathrm{L} 2$ is represented by ethylene with two terminal heteroatoms, oxygen, and nitrogen that has a methyl branch. As shown, among the glitazones, it follows the SAR guide by displaying the maximum number of atoms (four carbon/hetero atoms length). Whilst, L2 in pioglitazone is represented by an ethylene group connected to just one terminal oxygen atom. The " $U$ " geometry of the binding conformation displayed in Figure 8 for rosiglitazone indicates the vital role of L2. This linker should provide sufficient flexibility to achieve this ideal "U" shape binding conformation. Thus, the binding efficacy would be mainly influenced by chain length besides the heteroatoms that exist in the chain.

A group of conventional glitazones with diverse linkers is shown in Figure 9. This change leads to different ligands with different binding modes and outcomes. A very short $\mathrm{L} 2$ is introduced for ciglitazone (6) that is considered a prototype for glitazones. Compared to rosiglitazone, ciglitazone presents oxymethylene linker $\left(-\mathrm{O}-\mathrm{CH}_{2}-\right)$ and due to its high toxicity, it has been withdrawn from the market. Similar to ciglitazone, L2 is also represented by the oxymethylene linker in troglitazone (7) and rivoglitazone (8). Their high adverse effects led to their use them. ${ }^{48}$

The troglitazone structure was modified into various analogs and their activities were assessed against glucose and triglyceride plasma levels. With maintaining the $\mathrm{L} 2$ link $\left(-\mathrm{O}-\mathrm{CH}_{2}-\right)$ in troglitazone, L1, and the central aromatic ring were modified to an unsaturated branched linker and to a naphthyl spacer, respectively. As a result, analog 9 (Figure 9) was designed and synthesized. This analog displayed a hypoglycemic effect by decreasing glucose level, but the triglyceride level did not change. ${ }^{49}$

Modifying L2 and the hydrophobic tail to an amido-methylene group and trifluoromethyl phenyl ring, respectively, led to get compound 10, called KRP-297. Unfortunately, this drug displayed a carcinogenic effect and was withdrawn from

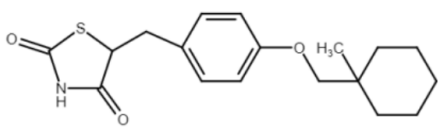

Compound 6

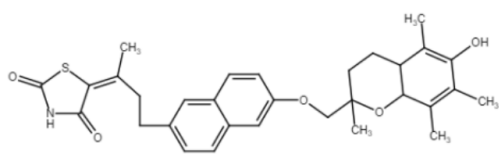

Compound 9

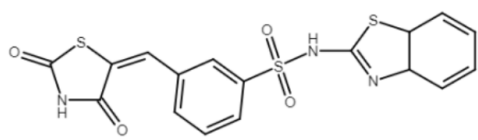

Compound 12

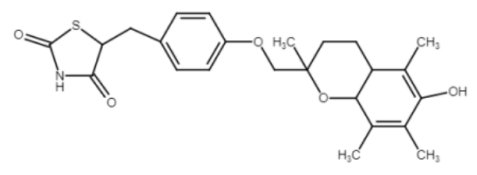

Compound 7

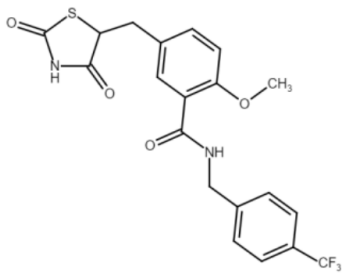

Compound 10

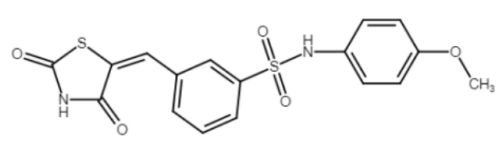

Compound 13

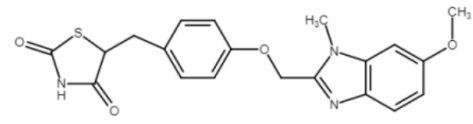

Compound 8

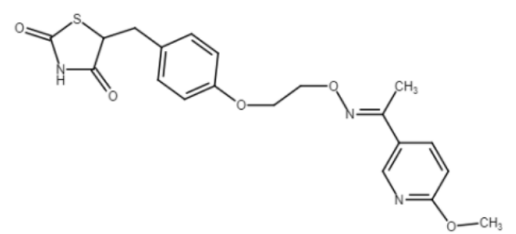

Compound 11

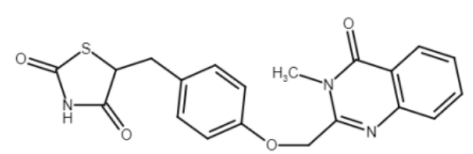

Compound 14

Figure 9. Compound 6, 7 and 8 with short linker, L2. Compound 9 represents troglitazone analogue. Compounds 10, 11, 12 and 13 are TZDs with modifications on L2. Compound 14 is balaglitazone 88-52,58 $^{2}$

TZDs: Thiazolidinediones, L2: Linker-2 
therapeutic use in spite of acting as a dual agonist ligand for PPAR- $\alpha / \gamma^{50}$ Extending L2 to constitute six-carbon/heteroatoms chain led to produce compound 11. This compound revealed good antihyperglycemic, antihyperlipidemic, and anti-obesity properties. The oxime function group exists in the L2 linker, through boosting the hydrophobic interactions with the receptor, plays an important role in binding. ${ }^{51}$ Attempts to insert unusual moieties like sulfonyl groups into L2 linker led to finding new antidiabetic agents related to glitazones. A moderate antidiabetic agent (compound 12) was produced by introducing a benzothiazole group as a high lipophilic tail and a sulfonyl moiety to $L 2$. This led to finding a series of glitazone derivatives bearing sulfonyl $\mathrm{L} 2$ that could be administered orally like compound 13. The sulfonyl moiety as the weakest acceptor is suggested to form short $\mathrm{H}$-bonds with the polar residues at the entrance of LBD. ${ }^{52}$

\section{Modifications on lipophilic tail}

Regarding the ligand-receptor interaction, in general, extending the hydrophobic area that takes part in the reaction with the receptor moieties leads to enhanced binding efficiency and hence, improves binding affinity. ${ }^{53}$ However, the binding affinity here is highly influenced by the desolvation phenomenon presented by the lipophilic moieties of both the ligand and receptor, during the binding process.44,54 Thus, to decrease the desolvation effect and hence enhance the binding energy, the lipophilic binding cavities of the receptor should be matched properly with lipophilic binding groups of the ligand. Moreover, the hydration status of the receptor as an apo-form (unbound state) should be verified. These two hints are considered the key factors in docking the ligands with the receptors. ${ }^{55,56}$ Because of proving that filling $55 \%$ of the targeted protein volume represents the optimal binding state, the size of the lipophilic moieties is critical. ${ }^{57}$ The binding sites P3 and P4 exist in the LBD of PPAR- $\gamma$ exhibit large lipophilic cavities.

It is interesting to mention that the strong agonist antidiabetic agent rosiglitazone (1) makes a lipophilic interaction only with the P3 binding site. However, the lipophilic tail group is represented by a large size pyridine ring, its molecular structure is considered small and this large ring is unable to reach the $\mathrm{P} 4$ binding site. In contrast, as shown in Figure 9, the lipophilic tail group regarding balaglitazone (14) is represented by a bulky moiety of benzopyrimidinone that makes a contact with both binding sites P3 and P4. This action at both lipophilic sites has a good correlation with it is partial agonist action on PPAR- $\gamma$. Representing the hydrophobic tail moiety with a fused heterocyclic or polynuclear aromatic ring would provide additional lipophilic interaction and extend the volume occupied at the binding cavity and hence, the mechanism of action, binding efficacy would be changed. Balaglitazone, developed by Dr. Reddy's labs, completed a phase III trial in Denmark, Finland and Sweden. However of exhibiting superior action compared to pioglitazone such as more potent, minor cardiac arrest, minor risk of fluid retention, and no adverse effects on bone, the clinical studies discontinued due to not demonstrating the competitive potential effect compared to similar products already marketed for T2DM. ${ }^{58}$

Thus, due to the beneficial therapeutic actions associated with the absence of usual adverse effects, the PPAR- $\gamma$ partial agonists currently attract a lot of interest. Studies have reported that the binding interactions finally change the transcriptional outcomes because of inducing specific conformational variations. To enhance the therapeutic profiles of antidiabetic drugs like pioglitazone and rosiglitazone by diminishing their side effects but while retaining the antidiabetic and antihyperlipidemic action, the co-regulators are considered to be key factors that could be slightly modulated to fine-turn the final pharmacological action. Subjecting the present glitazones drugs for structural modifications could be a reliable strategy to achieve specific modulation of the transcriptional activity. ${ }^{59,60}$

Various ring structures diverse in hydrophobicity and size could be used to identify the topology structure of glitazones. With respect to the lipophilic tail and the topology structure, the TZD analogs are classified into two main types: Conventional and non-conventional TZD. The conventional class fits into the topology of synthetic PPAR- $\gamma$ and, based on the lipophilic tail, it further sub-classified into (a) pyridyl and pyrimidyl analogs that present large size rings as hydrophobic tail groups. (b) Naphthyl, styryl, diphenyloxy, and pyridyl-pyrrolidinyl analogs, the hydrophobic tails here are represented by bulky groups. And (c) miscellaneous like indolyl, pthalazinyl, quinazolinyl, quinoxalinyl, and benzpyryl (chroman) analogs. Regarding the non-conventional TZDs, that do not fit into the topology of synthetic PPAR- $\gamma$, are also sub-classified into the following: TZDs without characteristic lipophilic tail and TZDs without characteristic linker subclasses.

\section{Conventional TZDs}

\section{Pyridyl and pyrimidyl analog}

Figure 10 shows two pyridyl analogs (compound 15 and 16) and one pyrimidyl analog (compound 17). At micromolar concentrations, the agonistic activity of the pyridyl TZD analogs was reported with enhanced potency. With respect to pyridyl TZDs, L1 and L2 are represented by simple methylene groups attached to a central phenyl ring. Despite the high structural similarity, compound 15 revealed a higher agonistic activity than compound 16 . These results could be related to the stereochemistry of the pyridine ring, located at a more favorable position in compound 15 leads to better fitting in the lipophilic cavity. ${ }^{61,62}$

However, compound 17, a pyrimidyl TZD analog, displayed a superior clinical profile compared to the antidiabetic drugs; pioglitazone and rosiglitazone. It exhibited higher transcriptional and agonistic activity for PPAR- $\gamma$, lesser side effects, and better oral absorption. ${ }^{63}$ It suggested that the bulky lipophilic tail for compound 17, pyrimidine ring-substituted alkyl groups plays a significant role in these superior effects. This bulky tail is expected to obey $55 \%$ rule of the volume occupied, thus presenting a better affinity. 
<smiles>COc1ccc(CC2SC(=O)NC2=O)cc1Cc1ccccn1</smiles>

Compound 15<smiles>COc1ccc(/C=C2/SC(=O)NC2=O)cc1-c1cc(C)cc2c1C(C)(C)CCC2(C)C</smiles>

Compound 18<smiles>O=C1NC(=O)/C(=C/c2ccc(OCC3CCCN3c3ccccn3)cc2)S1</smiles>

Compound 21<smiles>O=C1CC(Cc2ccc(OCCC3N=C(O)c4ccccc4C3=O)cc2)C(=O)N1</smiles>

Compound 24<smiles>CCCCC(CCOc1ccc(CC2CC(=O)CN2)cc1)C1=CC2C=CC=CC2O1</smiles>

Compound 27<smiles>O=C1S/C(=C/c2ccc(-c3cc(=O)c4ccccc4o3)cc2)C(=O)C1Cc1ccccc1</smiles>

\section{Compound 30}<smiles>COC(=O)c1cc(CC2SC(=O)NC2=O)ccc1OC</smiles><smiles>COc1ccc(CC2SC(=O)NC2=O)cc1Cc1ccncc1</smiles>

Compound 16

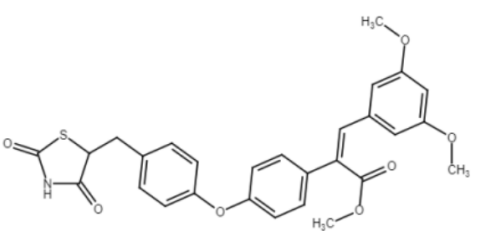

Compound 19<smiles>O=C1NC(=O)C(Cc2ccc(OCCN3C=CC4C=CC=CC43)cc2)S1</smiles>

Compound 22<smiles>CC1C(=O)c2ccccc2NC1COc1ccc(CC2SC(=O)NC2=O)cc1</smiles>

Compound 25<smiles></smiles>

Compound 28<smiles>COc1cc(CC2SC(=O)NC2=O)ccc1C#CCC1c2ccccc2Oc2ccccc21</smiles>

Compound 31<smiles>CCC1NC(C)=CC(=O)N1CCOc1ccc(CC2SC(=O)NC2=O)cc1</smiles>

Compound 17<smiles>CCCc1cc(Oc2ccccc2)ccc1OCCCOc1cccc(C2(C)SC(=O)C(=O)CC2=O)c1</smiles>

Compound 20<smiles>COc1ccc2nc(COc3ccc(CC4SC(=O)NC4=O)cc3)n(C)c2n1</smiles>

Compound 23<smiles>O=C1Cc2cc(O)c(O)cc2C(CCOc2ccc(/C=C3\SC(=O)NC3=O)cc2)C1</smiles>

Compound 26<smiles>O=C1NC(=O)C(Cc2ccc(OCCC3COc4ccccc4C3=O)cc2)S1</smiles>

Compound 29<smiles>O=C1NC(=O)C(C#Cc2ccccc2)(Cc2ccccc2)S1</smiles>

Compound 33

\section{Compound 34}

Figure 10. Examples of conventional (compound 15-31) and un-conventional (compound 33 and 34) thiazolidinediones s1-77 $^{61}$ 
Naphthyl, styryl, diphenyloxy, and pyridyl-pyrrolidinyl analogs These analogs are characterized by the presence of bulky hydrophobic tails, some examples are shown in Figure 10. Compound 18 , a tetrahydronaphthalene analog reported with a moderate hypoglycemic effect, consists of a bulky naphthyl lipophilic tail connected directly to a central phenyl ring, L1 is an unsaturated linker. ${ }^{64}$ Because of the absence of L2 and the short length of $L 1$, the ability of this compound to interact properly with the binding sites $\mathrm{P} 3$ and $\mathrm{P} 4$ is very minimal. Compound 19, a styryl analog, exhibited comparable PPAR- $\gamma$ agonistic action associated with a better anti-diabetic effect. ${ }^{65}$ A considerable effect on insulin sensitivity besides exhibiting dual agonistic action on PPAR- $\alpha / \gamma$ was reported for compound 20 , which contains a bulky diphenyloxy lipophilic tail and an extended L2 chain of five atoms. ${ }^{66}$ The hydrophobic tail moiety and L1 linker in compound 21 are represented by a pyrrolidine ring directly attached to the pyridine ring and an unsaturated linker, respectively. This compound displayed a better antidiabetic and antihyperlipidemic effect compared to troglitazone drug. ${ }^{67}$

\section{Miscellaneous}

Figure 10 displays the structures of compounds 22 and 23 representing indole and imidazopyridyl derivatives, respectively. Compound 22 exhibited an excellent profile with better insulin sensitivity if compared to the rosiglitazone drug. Also, it exhibited a superior antihyperlipidemic effect compared with troglitazone and rosiglitazone drugs by improving the HDL cholesterol levels. ${ }^{68}$ The imidazopyridyl derivative (23) also revealed promising outcomes as a hypoglycemic agent but with less adverse effects often associated with rosiglitazone, like cardiovascular diseases. ${ }^{69}$ The indole and imidazopyridyl rings behaved as the best lipophilic moieties to represent the lipophilic tail fraction to minimize the side effects besides improving the agonist activity for PPAR- $\gamma$. This proposes that the lipophilic indole and imidazopyridyl residues can interact and fill the lipophilic binding cavities properly; thus the transcriptional activity is specially modulated that usually leads ultimately to reducing adverse effects.

Compounds 24, 25, and 26, shown in Figure 10, represent the pthalazinyl, quinazolinyl, and quinoxalinyl analogs, respectively. Compound 26 displayed a higher PPAR- $\gamma$ agonistic effect compared to compound 24 (pthalazinyl derivative). Additionally, it is approved that the presence of activating groups like methyl at positions 6 and 7 on quinoxalinyl ring, compared to analogs containing deactivating groups like the phenyl ring, showed excellent hypoglycemic and antihyperlipidemic activity. Regarding quinoxalinyl analogs, a significant antihyperlipidemic effect has been reported with the analogs containing shorter L2 lengths.

To achieve an ideal PPAR- $\gamma$ agonistic activity, the length of $L 2$ should be represented by a maximum of three atoms. Due to the steric effect, as suggested, the pthalazinyl and quinazolinyl analogs revealed less PPAR- $\gamma$ agonistic activity compared to quinoxalinyl analogs. This steric effect increases improper contact within the lipophilic binding cavity. ${ }^{70,71}$
Assessing the hypoglycemic and antihyperlipidemic effects of molecule 27, a benzoxazolyl analog, and molecule 28 proved some activities (Figure 10). Representing the L2, in both derivatives, with $n$-propyl substituent led to getting the extreme effect. ${ }^{72,73}$ Regarding compound 29, a benzoxazinyl analog, was reported with a dual PPAR- $\alpha / \gamma$ agonistic activity, indicating that, in designing, the ring expansion strategy could be favorable to target both receptors, PPAR- $\alpha$ and $\gamma$ (Figure 10).

Analyzing these three series analogs from the structural viewpoint demonstrated that, the molecules reported with an optimum agonistic activity hold short linkers of two to three atoms. This optimal activity turns to a full PPAR- $\gamma$ agonist if these short linkers are extended to 4 atoms length. TZD analogs with a bulky lipophilic tail like benzoxazine moiety connected to ideal L2 (three atoms) and L1 lengths would result in a potential dual agonistic activity besides lacking adverse effects. ${ }^{74}$

Compound 30, a benzpyryl derivative, exhibited a mild activity on elevated lipid and glucose levels. As shown in Figure 10, compound 18 lacks L2 and has a substituent on the nitrogen N-3 of the TZD ring. ${ }^{75}$ Also, Figure 10 shows the chemical structure of compound 31 in which, the lipophilic tail is represented by a bulky dibenzpyryl ring whilst, L2 is an unsaturated chain of three atoms. This molecule exhibited an agonistic activity for all receptor isoforms, PPAR- $\alpha,-\beta$, and $-\gamma^{76}$

\section{Non-conventional TZDs}

This class of TZDs represents, as mentioned before, the analogs which do not follow the classical topology of synthetic PPAR- $\gamma$. A series of non-conventional TZD-based amide analogs were designed and synthesized besides monitoring their blood glucose-lowering action and adverse effects. As shown in Figure 10, this group lacks L2, the lipophilic tail group is represented by a simple phenyl ring, and the L1 moiety is an unsaturated link of one carbon atom. A moiety of pyrazole rings connected directly to an aromatic ring applied as the central phenyl ring in which, the nature of this aromatic ring is the only difference within these analogs.

Based on the recorded data in Table 1, when the aromatic ring is a phenyl ring (32a) or 4-fluorophenyl (32b), a moderate hypoglycemic effect is obtained. Replacing the fluorine with a chlorine atom led to compound $32 \mathrm{c}$ that displayed the most promising results compared to other analogs (highest hypoglycemic effect). The results obtained using molecular docking of compound 32c against PPAR- $\gamma$ showed excellent $\mathrm{H}$-bond interactions with ILE-281 and SER-342 amino acids, with LYS-367 via halogen interaction and with ARG-288 via $\pi-\pi$ interaction and these findings could explain the superior action of 32c. Also, this molecule elevated the gene expression of PPAR $-\gamma$ by 2.1 fold accompanied by transactivation effects equals to $53.65 \%$, which is comparable to pioglitazone and rosiglitazone with $62.21 \%$ and $86.4 \%$ transactivation, respectively. Furthermore, the molecule did not display any noticeable hepatotoxic effect or significant change in body weight. Furthermore, compounds $32 \mathrm{i}$ and $32 \mathrm{l}$, similar to $32 \mathrm{a}$ and $32 \mathrm{~b}$, displayed moderate effects whilst, $32 \mathrm{n}$ and $32 \mathrm{~m}$ 
Table 1. Amide-based thiazolidinedione analogues ${ }^{15}$

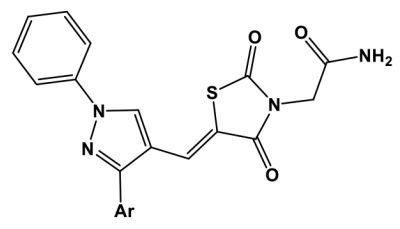

\begin{tabular}{|c|c|c|c|c|c|}
\hline \multicolumn{6}{|c|}{$32 a-q$} \\
\hline Compound & $\mathrm{Ar}$ & Compound & $\mathrm{Ar}$ & Compound & $\mathrm{Ar}$ \\
\hline & Phenyl & & 4-Methylphenyl & & 4-Nitrophenyl \\
\hline $32 a$ & & $32 g$ & & $32 \mathrm{~m}$ & \\
\hline
\end{tabular}

\section{4-Fluorophenyl}

$32 b$<smiles>Nc1ccc(F)cc1</smiles>

4-Clorophenyl

$32 c$<smiles>[N]c1ccc(Cl)cc1</smiles>

3,4-Diclorophenyl

$32 d$<smiles>Cc1ccc(Cl)c(Cl)c1</smiles>

2,4-Diclorophenyl<smiles>Nc1ccc(Cl)cc1Cl</smiles>

$32 k$

$32 \mathrm{j}$

$32 e$
4-Hydroxyphenyl<smiles>[N]c1ccc(O)cc1</smiles>

3-Hydroxyphenyl<smiles>Oc1cccc(O)c1</smiles>

3,4-Dihydroxyphenyl<smiles>Cc1ccc(O)cc1O</smiles>

4-Methoxyphenyl<smiles>COc1ccc(C)cc1</smiles>

3-Nitrophenyl<smiles>Cc1cccc([N+](=O)[O-])c1</smiles>

Thiphene-2-yl<smiles>Nc1cccs1</smiles>

3,4-Dimethoxyphenyl

$32 f$

321<smiles>COc1ccc(C)cc1OC</smiles> 
showed significant blood glucose-lowering effects compared to reference drugs.

Evaluating hepatic protectivity of the most advantageous compounds 32c, 32e, and 32m, showed an excellent hepatoprotective effect by returning alkaline phosphatase, alanine transaminase, and aspartate transaminase enzyme levels to normal ranges. Compound $32 \mathrm{n}$ displayed excellent hypoglycemic action but unfortunately, reported with mild liver. The other analogs did not display any favorable hypoglycemic effect. ${ }^{15}$

Additionally, Figure 10 displays two non-conventional analogs that contain neither specific bulky hydrophobic tails nor characteristic linkers. Compound 33 elicited a moderate hypoglycemic effect, whilst antihyperglycemic activity was reported for compound 34..$^{35,77}$

\section{Hybrid TZD analogs}

Based on the fact that: If two agents present independent pharmacological activity is linked covalently, a synergistic activity could be achieved. This is the concept of pharmacophore merging or hybridization. Very diverse compounds could be used to this strategy, including polypeptides, amino acids, small organic and inorganic molecules, natural ligands, and nucleic acids. Through the rational approach, using compound libraries or computational techniques in drug design, the molecules to be subjected are identified. ${ }^{78}$ Figure 11 shows two examples of hybrid TZD analogs. Because of hybridizing a classical TZD structure contains L2, central phenyl ring, and L1 with a potent antioxidant $\alpha$-lipoic acid to represent the hydrophobic tail (compound 35). This hybrid analog showed an outstanding pharmacological profile exemplified by presenting a potent PPAR- $\gamma$ agonistic activity accompanied by an extreme reduction in triglyceride levels. ${ }^{79}$ Compound 36 represents a novel hybrid analog of TZD, in which, a phenylalanine amino acid is substituted on the ring nitrogen of TZD. The polar residues existing at the head of phenylalanine create additional hydrogen bond interactions, which participate mainly in enhancing its binding efficiency. This analog was reported with a synergistic activity at nanomolar levels. ${ }^{80}$

The hybrid molecules, in application in T2DM, were also effective to control the skin inflammatory conditions, vascular restenosis, and obesity. Additionally, anti-inflammatory and anti-malignant activities have been reported for several other hybrid agents. Thus, for significant antidiabetic effects along

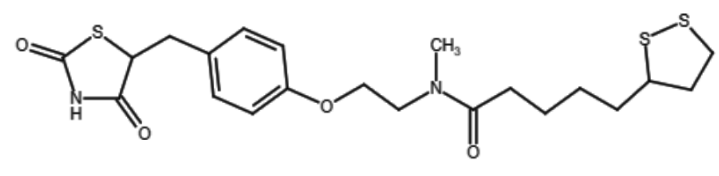

Compound 35 with minimum cardiovascular complications, hybrid molecules are currently considered a novel class of PPAR- $\gamma$ agonists. ${ }^{81}$

\section{FFA Receptor 1 (FFAR1) as emerging target for TZDs}

Several favorable research attempts have recently been focused on treating DM by regulating insulin secretion using FFA. It has been recently proved that the medium to long-chain FAs induce insulin release by stimulating FFAR1, also termed as G-protein coupled receptor 40 . This stimulation will ultimately improve glucose-dependent secretion of insulin from pancreatic $\beta$-cells by affecting the protein kinase- $C$ pathway besides other several signaling pathways. ${ }^{82} \mathrm{~A}$ short to medium carbon chain length presents ten carbon atoms minimum, contains a potential free carbonyl group and unsaturated or saturated carbon is considered the proposed pharmacophore to stimulate these targets. $^{83}$

Lately, FFAR1 has attracted attention because it has been proved to be stimulated positively by TZD hypoglycemic agents, however, the mechanism of activation. ${ }^{84}$ Hence targeting the FFAR1 to treat T2DM currently presents a vast scope for developing TZDs as agonists/antagonists ligands. Compounds 37 and 38, shown in Figure 12, represent new TZD analogs that were reported with a dual FFAR1 and PPAR- $\gamma$ agonistic activity at micromolar levels. This led to a boost in both insulin sensitivity and release. As shown, these analogs follow the conventional topology of the synthetic agonists in which, the biphenyl and benzimidazole bulky groups are used to represent the lipophilic tail of compounds 36 and 37, respectively. ${ }^{85}$

The activation of FFAR1 by the TZD analog rosiglitazone, as demonstrated by a study, led to improve PPAR- $\gamma$ efficiency by regulating signal transduction. ${ }^{86}$ Hence, this regulating effect of these dual agonistic ligands is expected to play a vital role in glucose homeostasis. This new-found concept regarding the advantageous effects of dual agonistic agents has unveiled reliable novel strategies to dominate the T2DM disease.

\section{CONCLUSION}

Studying the SAR of TZDs led to discover plentiful diverse derivatives, which mean that TZDs could tolerate the presence of diverse hydrophobic tails, central aromatic rings, and linkers that finally resulted in modifying their pharmacodynamic properties by enhancing selectivity and potency along with decreasing adverse effects. As well, some

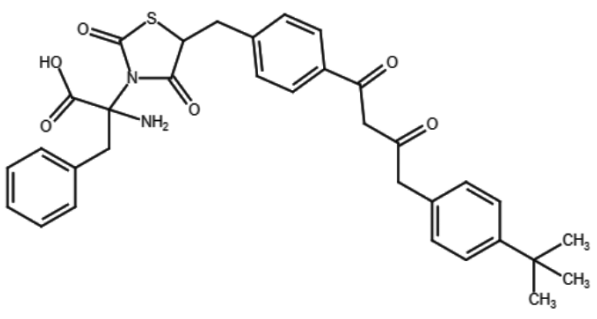

Compound 36

Figure 11. Hybrid compounds of thiazolidinediones ${ }^{79,80}$ 


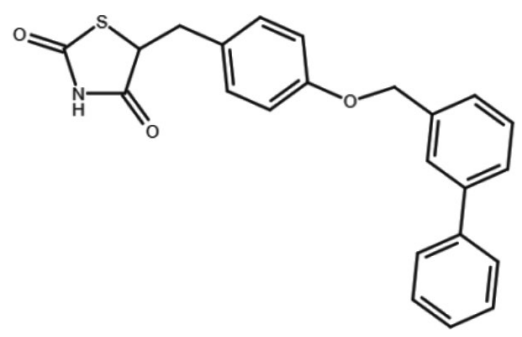

Compound 37

Figure 12. Thiazolidinedione dual PPAR- $\gamma$ and FFAR1 agonists ${ }^{85}$ PPAR: Peroxisome proliferator-activated receptors, FFAR: FFA receptor 1

modifications led to improve their pharmacokinetic properties such as upgrading oral bioavailability. Often, TZDs present a bulky structure that is considered substantial to create proper contact with the large lipophilic and polar cavities of the LBD of the target. Based on the previous studies, the main headlines that could summarize the SAR of TZDs as promising ligands to treat T2DM are the methylene group (one carbon atom) is suggested as the best choice to represent L1 moiety to connect TZD acidic ring with the central phenyl ring. Any advantageous effects had not been achieved in the case of the insertion of a heteroatom in this linker. Regarding the central phenyl ring, it is commonly occupied by a simple phenyl ring. A dual agonistic effect could be obtained if the phenyl ring is expanded or replaced by a naphthyl ring. The insertion of electron-withdrawing groups $\left(\mathrm{Cl}, \mathrm{F}, \mathrm{NO}_{2}\right)$ into central aromatic moieties was more profound in regulating glucose level toward the normal range and maximizing gene expression compared with moieties accommodating electronwithdrawing groups $\left(\mathrm{CH}_{3}, \mathrm{OH}, \mathrm{OCH}_{3}\right)$. Substituting the para position with electron releasing groups showed a more potent hypoglycemic effect than the meta position. Increasing the number of electron releasing substituents led to better performance. With respect to $L 2$, the carbon chain between the central phenyl ring and the lipophilic tail should be at least two atoms in length. To output optimum agonistic activity, L2 chain should be represented by a maximum four atom chains that accommodates at least one heteroatom. With regard to the lipophilic tail group, the size plays a significant role in determining the efficacy of binding. In conclusion, TZDs with large lipophilic tail and short/lengthy connectors act as potent PPAR $-\gamma$ agonists. Whilst, a dual PPAR- $\alpha / \gamma$ or PPAR $-\gamma /$ FFAR1 agonistic activity could be achieved using a bulky hydrophobic tail and short linkers. These agonist ligands exhibit different binding modes.

Because of the structural requirements to achieve a dual PPAR$\alpha / \gamma$ agonistic effects are still not completely identified, TZD analogs exhibiting dual activity is still rare. Further in-depth studies regarding the structure and action mechanisms of dual agonists of PPAR/FFAR1 or PPAR are required. This could be accomplished through applying advanced molecular modeling techniques.

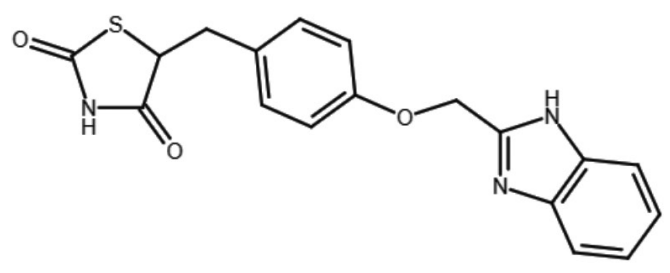

Compound 38

Peer-review: Externally peer-reviewed.

Authorship Contributions

Concept: T.Ö., Design: M.T.Q., Data Collection or Processing: M.T.Q., I.A., Analysis or Interpretation: M.T.Q., I.A., T.Ö., Literature Search: M.T.Q., I.A., T.Ö., Writing: M.T.Q., I.A.

Conflict of Interest: No conflict of interest was declared by the authors.

Financial Disclosure: The authors declared that this study received no financial support.

\section{REFERENCES}

1. American Diabetes Association. Diagnosis and classification of diabetes mellitus. Diabetes Care. 2014;37(Suppl 1):S81-90.

2. Craig ME, Hattersley A, Donaghue KC. Definition, epidemiology and classification of diabetes in children and adolescents. Pediatr Diabetes. 2009;10(Suppl 12):3-12.

3. Craig ME, Jefferies C, Dabelea D, Balde N, Seth A, Donaghue KC; International Society for Pediatric and Adolescent Diabetes. ISPAD Clinical Practice Consensus Guidelines 2014. Definition, epidemiology, and classification of diabetes in children and adolescents. Pediatr Diabetes. 2014:15(Suppl 20):4-17.

4. Zaccardi F, Webb DR, Yates T, Davies MJ. Pathophysiology of type 1 and type 2 diabetes mellitus: a 90-year perspective. Postgrad Med J. 2016;92:63-69.

5. Maahs DM, West NA, Lawrence JM, Mayer-Davis EJ. Epidemiology of type 1 diabetes. Endocrinol Metab Clin North Am. 2010;39:481-497.

6. Saeedi P, Salpea P, Karuranga S, Petersohn I, Malanda B, Gregg EW, Unwin N, Wild SH, Williams R. Mortality attributable to diabetes in 20-79 years old adults, 2019 estimates: results from the International Diabetes Federation Diabetes Atlas, $9^{\text {th }}$ edition. Diabetes Res Clin Pract. 2020;162:108086.

7. Patterson CC, Karuranga S, Salpea P, Saeedi P, Dahlquist G, Soltesz G, Ogle GD. Worldwide estimates of incidence, prevalence and mortality of type 1 diabetes in children and adolescents: results from the International Diabetes Federation Diabetes Atlas, $9^{\text {th }}$ edition. Diabetes Res Clin Pract. 2019;157:107842.

8. American Diabetes Association. 13. children and adolescents: standards of medical care in diabetes-2019. Diabetes Care. 2019;42(Suppl 1):S148-S164. 
9. Xu G, Liu B, Sun Y, Du Y, Snetselaar LG, Hu FB, Bao W. Prevalence of diagnosed type 1 and type 2 diabetes among US adults in 2016 and 2017: population based study. BMJ. 2018;362:k1497.

10. IDF diabetic atlas $9^{\text {th }}$ edition. Global diabetic data report $2010-2045$. Int Diab Fed. 2019. Available from: https://diabetesatlas.org/data/en/ world/

11. Type 2 diabetes in children and adolescents. American Diabetes Association. Pediatrics. 2000;105(3 Pt 1):671-680.

12. Sugihara S, Sasaki N, Kohno H, Amemiya S, Tanaka T, Matsuura N; Committee for the Medical Treatment of Childhood-Onset Type 2 Diabetes Mellitus, The Japanese Society for Pediatric Endocrinology. Survey of current medical treatments for childhood-onset type 2 diabetes mellitus in Japan. Clin Pediatr Endocrinol. 2005;14:65-75.

13. Chiang JL, Kirkman MS, Laffel LM, Peters AL; Type 1 Diabetes Sourcebook Authors. Type 1 diabetes through the life span: a position statement of the American Diabetes Association. Diabetes Care. 2014;37:2034-2054.

14. Kirpichnikov D, McFarlane SI, Sowers JR. Metformin: an update. Ann Intern Med. 2002;137:25-33.

15. Naim MJ, Alam MJ, Nawaz F, Naidu VGM, Aaghaz S, Sahu M, Siddiqui $\mathrm{N}$, Alam O. Synthesis, molecular docking and anti-diabetic evaluation of 2,4-thiazolidinedione based amide derivatives. Bioorg Chem. 2017;73:2436.

16. Franciosi M, Lucisano G, Lapice E, Strippoli GF, Pellegrini F, Nicolucci A. Metformin therapy and risk of cancer in patients with type 2 diabetes: systematic review. PLoS One. 2013;8:e71583.

17. Hauner $\mathrm{H}$. The mode of action of thiazolidinediones. Diabetes Metab Res Rev. 2002;18(Suppl 2):S10-S15.

18. Miyazaki Y, Mahankali A, Matsuda M, Glass L, Mahankali S, Ferrannini E, Cusi K, Mandarino LJ, DeFronzo RA. Improved glycemic control and enhanced insulin sensitivity in type 2 diabetic subjects treated with pioglitazone. Diabetes Care. 2001;24:710-719.

19. Parulkar AA, Pendergrass ML, Granda-Ayala R, Lee TR, Fonseca VA. Nonhypoglycemic effects of thiazolidinediones. Ann Intern Med. 2001;134:61-71.

20. Vigneri R. Diabetes: diabetes therapy and cancer risk. Nat Rev Endocrinol. 2009;5:651-652.

21. Michalik L, Wahli W. Involvement of PPAR nuclear receptors in tissue injury and wound repair. J Clin Invest. 2006;116:598-606.

22. Evans RM, Barish GD, Wang YX. PPARs and the complex journey to obesity. Nat Med. 2004;10:355-361.

23. Balakumar P, Rose M, Ganti SS, Krishan P, Singh M. PPAR dual agonists: are they opening Pandora's box? Pharmacol Res. 2007;56:91-98.

24. Lemberger T, Braissant O, Juge-Aubry C, Keller H, Saladin R, Staels B, Auwerx J, Burger AG, Meier CA, Wahli W. PPAR tissue distribution and interactions with other hormone-signaling pathways. Ann N Y Acad Sci. 1996;804:231-251.

25. Wagner ER, He BC, Chen L, Zuo GW, Zhang W, Shi Q, Luo Q, Luo X, Liu B, Luo J, Rastegar F, He CJ, Hu Y, Boody B, Luu HH, He TC, Deng ZL, Haydon RC. Therapeutic implications of PPAR gamma in human osteosarcoma. PPAR Res. 2010;2010:956427.

26. Viswakarma N, Jia Y, Bai L, Vluggens A, Borensztajn J, Xu J, Reddy JK. Coactivators in PPAR-regulated gene expression. PPAR Res. 2010;2010:250126.
27. Zoete V, Grosdidier A, Michielin O. Peroxisome proliferator-activated receptor structures: ligand specificity, molecular switch and interactions with regulators. Biochim Biophys Acta. 2007;1771:915-925.

28. Brown JD, Plutzky J. Peroxisome proliferator-activated receptors as transcriptional nodal points and therapeutic targets. Circulation. 2007;115:518-533.

29. Bain DL, Heneghan AF, Connaghan-Jones KD, Miura MT. Nuclear receptor structure: implications for function. Annu Rev Physiol. 2007;69:201-220.

30. Khorasanizadeh S, Rastinejad F. Nuclear-receptor interactions on DNAresponse elements. Trends Biochem Sci. 2001;26:384-390.

31. Nagy L, Schwabe JW. Mechanism of the nuclear receptor molecular switch. Trends Biochem Sci. 2004:29:317-324.

32. Gampe RT Jr, Montana VG, Lambert MH, Miller AB, Bledsoe RK, Milburn MV, Kliewer SA, Willson TM, Xu HE. Asymmetry in the PPARgamma/RXR alpha crystal structure reveals the molecular basis of heterodimerization among nuclear receptors. Mol Cell. 2000;5:545-555.

33. Xu HE, Lambert MH, Montana VG, Plunket KD, Moore LB, Collins JL, Oplinger JA, Kliewer SA, Gampe RT Jr, McKee DD, Moore JT, Willson TM. Structural determinants of ligand binding selectivity between the peroxisome proliferator-activated receptors. Proc Natl Acad Sci U S A. 2001;98:13919-13924.

34. Sheu SH, Kaya T, Waxman DJ, Vajda S. Exploring the binding site structure of the PPAR gamma ligand-binding domain by computational solvent mapping. Biochemistry. 2005;44:1193-1209.

35. Thangavel N, Al Bratty M, Akhtar Javed S, Ahsan W, Alhazmi HA. Targeting peroxisome proliferator-activated receptors using thiazolidinediones: strategy for design of novel antidiabetic drugs. Int $\mathrm{J}$ Med Chem. 2017;2017:1069718.

36. Gale EA. Lessons from the glitazones: a story of drug development. Lancet. 2001;357:1870-1875.

37. Waku T, Shiraki T, Oyama T, Fujimoto Y, Maebara K, Kamiya N, Jingami $\mathrm{H}$, Morikawa K. Structural insight into PPAR gamma activation through covalent modification with endogenous fatty acids. J Mol Biol. 2009;385:188-199.

38. Liberato MV, Nascimento AS, Ayers SD, Lin JZ, Cvoro A, Silveira RL, Martínez L, Souza PC, Saidemberg D, Deng T, Amato AA, Togashi M, Hsueh WA, Phillips K, Palma MS, Neves FA, Skaf MS, Webb P, Polikarpov I. Medium chain fatty acids are selective peroxisome proliferator activated receptor (PPAR) $\gamma$ activators and pan-PPAR partial agonists. PLoS One. 2012;7:e36297.

39. Kroker AJ, Bruning JB. Review of the structural and dynamic mechanisms of PPAR $\gamma$ partial agonism. PPAR Res. 2015;2015:816856.

40. Choi JH, Banks AS, Estall JL, Kajimura S, Boström P, Laznik D, Ruas JL, Chalmers MJ, Kamenecka TM, Blüher M, Griffin PR, Spiegelman BM. Antidiabetic drugs inhibit obesity-linked phosphorylation of PPARgamma by Cdk5. Nature. 2010;466:451-456.

41. Kaczanowski S, Zielenkiewicz P. Why similar protein sequences encode similar three-dimensional structures?. Theor Chem Acc. 2010;125:643650.

42. Russu WA. Thiazolidinedione anti-cancer activity: is inhibition of microtubule assembly implicated? Med Hypotheses. 2007;68:343-346.

43. Fajeelath F, Baskar L. Thiazolidinediones as a privileged structural scaffold in PPAR agonists: a review. Int J Pharm Chem. 2016;6:124-141.

44. Prabhakar C, Madhusudhan G, Sahadev K, Reddy CM, Sarma MR, Reddy GO, Chakrabarti R, Rao CS, Kumar TD, Rajagopalan R. Synthesis and 
biological activity of novel thiazolidinediones. Bioorg Med Chem Lett. 1998;8:2725-2730.

45. Adeghate E, Adem A, Hasan MY, Tekes K, Kalasz H. Medicinal chemistry and actions of dual and pan PPAR modulators. Open Med Chem J. 2011;5(Suppl 2):93-98.

46. Maji DE, Samanta S. A review on the role of peroxisome prolifertoractivated receptor- $\gamma$ agonists and hybrids in type 2 diabetes and cardiomyopathy. Asian J Pharm Clin Res. 2015;8:1-6.

47. Cercato C, Fonseca FA. Cardiovascular risk and obesity. Diabetol Metab Syndr. 2019;11:74.

48. Nadanaciva S, Will Y. Predicting drug-induced mitochondrial dysfunction, Wilson AG. New horizons in predictive toxicology: current status and application (1 ${ }^{\text {st }}$ ed). Royal Society of Chemistry; 2011:283-301.

49. Imran M, Ilyas B, Khan SA. Recent thiazolidinediones as antidiabetics. J Sc Res. 2007;66;99-109.

50. Nomura M, Kinoshita S, Satoh H, Maeda T, Murakami K, Tsunoda M, Miyachi H, Awano K. (3-substituted benzyl)thiazolidine-2,4-diones as structurally new antihyperglycemic agents. Bioorg Med Chem Lett. 1999;9:533-538.

51. Yanagisawa H, Fujita T, Fujimoto K, Yoshioka T, Wada K, Oguchi M, Fujiwara T, Horikoshi H. Oxime containing thiazolidinedione derivatives and analogs, their preparation, and their therapeutic use against diabetes and related conditions. European Pat. 1997;708:098.

52. Gorbitz CH, Etter MC. Hydrogen bonds to carboxylate groups. The question of three-centre interactions. J Chem Soc Perkin Trans 2. 1992;2:131-135.

53. Olsson TS, Williams MA, Pitt WR, Ladbury JE. The thermodynamics of protein-ligand interaction and solvation: insights for ligand design. J Mol Biol. 2008;384:1002-1017.

54. Berne BJ, Weeks JD, Zhou R. Dewetting and hydrophobic interaction in physical and biological systems. Annu Rev Phys Chem. 2009;60:85103.

55. Bissantz C, Kuhn B, Stahl M. A medicinal chemist's guide to molecular interactions. J Med Chem. 2010;53:5061-5084.

56. Peters JU, Weber S, Kritter S, Weiss P, Wallier A, Boehringer M, Hennig M, Kuhn B, Loeffler BM. Aminomethylpyrimidines as novel DPP-IV inhibitors: a 10(5)-fold activity increase by optimization of aromatic substituents. Bioorg Med Chem Lett. 2004;14:1491-1493.

57. Zürcher M, Diederich F. Structure-based drug design: exploring the proper filling of apolar pockets at enzyme active sites. J Org Chem. 2008; 73:4345-4361.

58. Agrawal R, Jain P, Dikshit SN. Balaglitazone: a second generation peroxisome proliferator-activated receptor (PPAR) gamma $(\gamma)$ agonist. Mini Rev Med Chem. 2012;12:87-97.

59. Higgins LS, Depaoli AM. Selective peroxisome proliferatoractivated receptor gamma (PPARgamma) modulation as a strategy for safer therapeutic PPARgamma activation. Am J Clin Nutr. 2010;91:267S-272S.

60. Doshi LS, Brahma MK, Bahirat UA, Dixit AV, Nemmani KV. Discovery and development of selective PPAR gamma modulators as safe and effective antidiabetic agents. Expert Opin Investig Drugs. 2010;19:489-512.

61. Fujimori S, Murakami K, Tsunoda M. Preparation of substituted benzylthiazolidine-2, 4-dione derivatives as ligands of human peroxisome proliferator-activated receptor. PCT Int Appl WO. 2001;1:350.
62. Fujimori S, Murakami K, Tsunoda M. Substituted benzylthiazolidine-2, 4-done dervatives. U.S. Patent no. 6,545,026 B1; date of patent: Apr. 8, 2003.

63. Madhavan GR, Chakrabarti R, Vikramadithyan RK, Mamidi RN, Balraju V, Rajesh BM, Misra P, Kumar SK, Lohray BB, Lohray VB, Rajagopalan $R$. Synthesis and biological activity of novel pyrimidinone containing thiazolidinedione derivatives. Bioorg Med Chem. 2002;10:2671-2680.

64. Pfahl M, Tachdijan C, Al-Shamma HA, Fanju A, Pleynet DP, Spran LW. Preparation of benzylidene thiazolidinediones and analoga as antidiabetics. PCT Int Appl WO, 00. 2001;16:122.

65. Neogi P, Lakner FJ, Medicherla S, Cheng J, Dey D, Gowri M, Nag B, Sharma SD, Pickford LB, Gross C. Synthesis and structure-activity relationship studies of cinnamic acid-based novel thiazolidinedione antihyperglycemic agents. Bioorg Med Chem. 2003;11:4059-4067.

66. Sahoo SP, Santini C, Boueres JK, Heck JV, Metzger E, Lombardo VK. Preparation of 5-(halo or alkyl)-5-aryl-2, 4-thiazolidinedione and oxazolidinedione derivatives as PPAR agonists. PCT Int Appl WO, 00. 2000;78:312.

67. Lohray BB, Bhushan V, Reddy AS, Rao PB, Reddy NJ, Harikishore P, Haritha N, Vikramadityan RK, Chakrabarti R, Rajagopalan R, Katneni K. Novel euglycemic and hypolipidemic agents. 4. Pyridyl- and quinolinylcontaining thiazolidinediones. J Med Chem. 1999;42:2569-2581.

68. Lohray BB, Bhushan V. Indole-containing thiazolidine-2, 4-diones as novel euglycemic and hypolipidemic agents: DRF-2189. Drugs Fut. 1999;24:751-757.

69. Oguchi M, Wada K, Honma H, Tanaka A, Kaneko T, Sakakibara S, Ohsumi J, Serizawa N, Fujiwara T, Horikoshi H, Fujita T. Molecular design, synthesis, and hypoglycemic activity of a series of thiazolidine-2,4diones. J Med Chem. 2000;43:3052-3066.

70. Kallam A R, Lohray V B, Alla S R, Pingali H, Ramanujam R. Compounds having antidiabetic, hypolipidemic, antihypertensive properties, process for their preparation and pharmaceutical compositions containing them. Dr. Reddy's Research Foundation, Hyderabad, India. U.S. Pat. No. 5,925,656. 1995 Jan 7: 08/476,385.

71. Madhavan GR, Chakrabarti R, Kumar SK, Misra P, Mamidi RN, Balraju V, Kasiram K, Babu RK, Suresh J, Lohray BB, Lohrayb VB, Iqbal J, Rajagopalan R. Novel phthalazinone and benzoxazinone containing thiazolidinediones as antidiabetic and hypolipidemic agents. Eur $\mathrm{J}$ Med Chem. 2001;36:627-637.

72. Jeon R, Park S. Synthesis and biological activity of benzoxazole containing thiazolidinedione derivatives. Arch Pharm Res. 2004:27:10991105.

73. Purohit SS, Veerapur VP. Benzisoxazole containing thiazolidinediones as peroxisome proliferator activated receptor- $\gamma$ agonists: design, molecular docking, synthesis \& antidiabetic studies. Sch Acad J Pharm. 2014;3:2637.

74. Madhavan GR, Chakrabarti R, Reddy KA, Rajesh BM, Balraju V, Rao PB, Rajagopalan R, lqbal J. Dual PPAR-alpha and -gamma activators derived from novel benzoxazinone containing thiazolidinediones having antidiabetic and hypolipidemic potential. Bioorg Med Chem. 2006;14:584591.

75. Blank B, DiTullio NW, Krog AJ, Saunders HJ. Synthesis and hypoglycemic activity of some substituted 2-arylthiazolo [3.2-a] pyridinium salts. J Med Chem. 1978;21:489-492.

76. Sattigeri JA, Salman M. Preparation of phenyl acetylene derivatives as agonists of PPAR receptors. PCT Int Appl WO. 2005;58:813:30. 
77. Onota M, Iwai Y. Preparation of benzoic acids and thiazolidinediones for $\mathrm{N}$-benzyldioxothiazolidinylbenzamides as antidiabetic agents. Japanese Pat 354664. 2001;354:664.

78. Müller-Schiffmann A, Sticht H, Korth C. Hybrid compounds: from simple combinations to nanomachines. BioDrugs. 2012;26:21-31.

79. Chittiboyina AG, Venkatraman MS, Mizuno CS, Desai PV, Patny A, Benson $\mathrm{SC}$, Ho Cl, Kurtz TW, Pershadsingh HA, Avery MA. Design and synthesis of the first generation of dithiolane thiazolidinedione- and phenylacetic acid-based PPARgamma agonists. J Med Chem. 2006;49:4072-4084.

80. Kumar BR, Soni M, Kumar SS, Singh K, Patil M, Baig RB, Adhikary L. Synthesis, glucose uptake activity and structure-activity relationships of some novel glitazones incorporated with glycine, aromatic and alicyclic amine moieties via two carbon acyl linker. Eur J Med Chem. 2011;46:835844.

81. Flora SJ. Structural, chemical and biological aspects of antioxidants for strategies against metal and metalloid exposure. Oxid Med Cell Longev. 2009;2:191-206.

82. Briscoe CP, Tadayyon M, Andrews JL, Benson WG, Chambers JK, Eilert MM, Ellis C, Elshourbagy NA, Goetz AS, Minnick DT, Murdock PR, Sauls
HR Jr, Shabon U, Spinage LD, Strum JC, Szekeres PG, Tan KB, Way JM, Ignar DM, Wilson S, Muir Al. The orphan G protein-coupled receptor GPR40 is activated by medium and long chain fatty acids. J Biol Chem. 2003;278:11303-11311.

83. Kotarsky K, Nilsson NE, Flodgren E, Owman C, Olde B. A human cell surface receptor activated by free fatty acids and thiazolidinedione drugs. Biochem Biophys Res Commun. 2003;301:406-410.

84. Salehi A, Flodgren E, Nilsson NE, Jimenez-Feltstrom J, Miyazaki J, Owman C, Olde B. Free fatty acid receptor 1 (FFA(1)R/GPR40) and its involvement in fatty-acid-stimulated insulin secretion. Cell Tissue Res. 2005;322:207-215.

85. Darwish KM, Salama I, Mostafa S, Gomaa MS, Helal MA. Design, synthesis, and biological evaluation of novel thiazolidinediones as PPAR $\gamma$ /FFAR1 dual agonists. Eur J Med Chem. 2016;109:157-172.

86. Wang S, Awad KS, Elinoff JM, Dougherty EJ, Ferreyra GA, Wang JY, Cai R, Sun J, Ptasinska A, Danner RL. G protein-coupled receptor 40 (GPR 40) and peroxisome proliferator-activated receptor $\gamma$ (PPAR $\gamma$ ): an integrated two-receptor signaling pathway. J Biol Chem. 2015;290:19544-19557. 